\title{
1 Assessing flooding impact to riverine bridges: an integrated analysis
}

2 Maria Pregnolato ${ }^{1 *}$, Andrew O. Winter ${ }^{2}$, Dakota Mascarenas ${ }^{2}$, Andrew D. Sen ${ }^{3}$, Paul Bates ${ }^{4}$, Michael R. Motley $^{2}$

${ }^{1}$ Dep. of Civil Engineering, University of Bristol, Bristol, BS8 1TR, UK

${ }^{2}$ Dep. of Civil and Environmental Engineering, University of Washington, Seattle, 98103, USA

$6{ }^{3}$ Dep. of Civil, Construction and Environmental Engineering, Marquette University, Milwaukee, 53233, USA

${ }^{4}$ School of Geographical Sciences, University of Bristol, Bristol, BS8 1RL, UK

*Correspondence to: Maria Pregnolato (maria.pregnolato@bristol.ac.uk)

Abstract. Flood events are the most frequent cause of damage to infrastructure compared to any other natural hazard, and global changes (climate, socio-economic, technological) are likely to increase this damage. Transportation infrastructure systems are responsible for moving people, goods and services, and ensuring connection within and among urban areas. A failed link in this system can impact the community by threatening evacuation capability, recovery operations and the overall economy. Bridges are critical links in the wider urban system since they are associated with little redundancy and a high (re)construction cost. Riverine bridges are particularly prone to failure during flood events; in fact, the risks to bridges from high river flows and bank erosion have been recognized as crucial at global level. The interaction among flow, structure and network is complex, and yet to be fully understood. This study aims to establish rigorous practices of Computational Fluid Dynamics (CFD) for modelling hydrodynamic forces on inundated bridges, and understanding the consequences of such impact on the surrounding network. Objectives of this study are to model hydrodynamic forces as demand on the bridge structure, to advance a reliability analysis of the structure under the modelled loading and to assess the overall impact at systemic level. The flood-prone City of Carlisle (UK) is used as case study and a proof of concept. Implications of the hydrodynamic impact on the performance and functionality of the surrounding transport network are discussed. This research will help to fill the gap between current guidance for design and assessment of bridges within the overall transport system.

\section{Introduction}

Bridges are crucial elements of the transport network given their high construction costs and the lack of alternatives routes. Man-made and natural events are a threat to bridge safety and network serviceability (Yang and Frangopol, 2020). Bridges act as bottlenecks for surrounding roads, and thus any service disruption can knock-out communities' access and connections, impair emergency planning and evacuation routes, as well as impact economies and businesses.

Some disruptive events are growing in frequency and severity. In particular, the impacts of flooding have been exacerbated in recent years by urbanisation (e.g. increase of impermeable surfaces), inappropriate land use in flood-prone areas and climate change. Rainfall events that lead to flooding are becoming more frequent and intense (Solomon et al., 2007), triggering bridge incidents and failures all over the world (Cumbria, UK, 2009; Drake, Colorado, 2013; Texas, 2018; Greece, 2020). As recent examples, Grinton Bridge in Yorkshire (North-West UK) and Keritis Bridge in Crete (Greece) were both washed away by floodwaters in 2019.

Riverine bridges are intrinsically vulnerable to flooding, as they are located in the area of the riverbed. Flood and scour represent the most frequent cause of bridge failures (>50\% of all failures; Wardhana and Hadipriono, 2003). Although, scour is recognized as the biggest threat, hydrodynamic forces could be as critical for bridge piers on bedrock (where scour is unlikely), and for the decks of all flooded bridges (Oudenbroek et al., 2018). In terms of consequences, natural hazards can damage bridges structurally (thus causing direct physical damages), but also cause travel time delays and rerouting that lead to indirect losses. Any bridge failure, whether structural or functional, has the potential to impose heavy consequences to 


$$
\begin{aligned}
& \frac{y_{s}}{y_{1}}=2.0 K_{1} K_{2} K_{3}\left(\frac{a}{y_{1}}\right)^{0.65} F_{1}^{0.43} \\
& \frac{y_{s}}{a}=\Phi_{1} \Phi_{2} \Phi_{3} \Phi_{4}
\end{aligned}
$$
system.

\subsection{Background} Highways England (HE, 2012). factor and $\Phi_{4}$ approaching flow angle factor.

owners or responsible authorities, as well as dire expenses. Therefore, understanding the potential impact of flooding to bridges is a compelling need of communities in areas of high flood risk.

Currently, a limited number of studies investigated the consequences of extreme flooding to bridges and the surrounding network (Yang and Frangopol, 2020). Practical application and case studies of real bridges tend to be focused on other natural hazards (e.g. earthquakes: Kilanitis and Sextos, 2019, Ertugay et al., 2016; Zhou et al., 2010). This study aims to establish rigorous practices of Computational Fluid Dynamics (CFD) for modelling hydrodynamic forces on inundated bridges, and understanding the consequences of flooding impact and potential functional loss on the surrounding network. Objectives of this study are to model hydrodynamic forces as demand on the bridge structure, to advance a reliability analysis of the structure under the modelled loading and to assess the overall impact at systemic level. Implications of the hydrodynamic impact on the performance and functionality of the surrounding transport network are discussed. This research will help to fill the gap between current guidance for design and assessment of bridges within the overall transport

Transport networks are formed by multiple links (i.e. roads), and their performance relies on parameters, such as availability of alternative routes (redundancy), road capacity, or traffic demand, among others. A bridge failure often means a critical link been taken out of service. Bridges are usually costly assets to be repaired, have little redundancy and are likely to be crossed by a high number of users, especially if belonging to strategic road networks (e.g. highways). Therefore, bridge closure or failure can impact the overall performance of the road network and the failure consequences have to be investigated from a system-perspective (Yang and Frangopol, 2020). The assessment of the systemic impact is a complex and multi-disciplinary problem, at the interface of hydrology, fluid dynamics, structural analysis and transport modelling. Scour damage is not the main focus of this paper and wide literature is already available (e.g. Pregnolato et al, 2020a; Wang et al., 2017; AASHTO, 2002). The HEC-18 pier scour equation is widely applied for both live-bed and clear-water pier scour to predict maximum pier scour depths (Eq. 1; Arneson et al., 2012). In the UK, the CIRIA scour model is used for local scour analysis (Kirby et al., 2015) for advanced assessments that explicitly consider flow conditions (Eq. 2), also adopted by

where $y_{s}$ is the scour depth (m), $y_{l}$ is the flow depth directly upstream of the pier (m), $K_{l}$ is the correction factor for pier nose shape, $K_{2}$ is the correction factor for angle of attack of flow, $K_{3}$ is the correction factor for bed condition, $a$ is the pier width (m), $F r_{l}$ is the Froude Number directly upstream of the pier; $\Phi_{1}$ is the shape factor, $\Phi_{2}$ water depth factor, $\Phi_{3}$ flow velocity

On the contrary, literature about modeling the hydrodynamic forces of the fluid on bridges due to riverine floods is limited, especially concerning fragility models or reliability analysis (Pregnolato, 2019; Gidaris et al., 2016). Existing research investigated tsunami impact to bridges (e.g. Motley and al., 2016; Lomonaco et al., 2018; Qin et al., 2016; Winter et al., 2017), where Computational Fluid Dynamics (CFD) techniques are used to compute hydrodynamic forces on bridges and components. Also, Kerenyi et al. (2009) applied CFD to compute hydrodynamic forces on inundated bridge decks, however the analysis was limited to the evaluation of drag and lift forces, without investigating impact and consequences. Multihazard studies investigated the interaction and implication of multiple hazards acting on a single structure (Gidaris et al., 
2016; Carey et al., 2019), especially between earthquake and tsunami. Other studies (Mondoro and Frangopol, 2018; Liu et al., 2018; Yilmaz et al., 2016) that tackled flood impact to bridges generally expressed the hazard through flood hazard curves, generated via flood-frequency analysis; however, a detailed hydraulic analysis was beyond the scope of their work. While tsunami loading of bridges will often result in much higher forces than riverine flows, the prevalence of riverine flooding relative to tsunami events necessitate further study and could have a far-reaching effect.

\subsection{Motivation and aim}

To the authors' knowledge, no study has comprehensively investigated the impact of high-river flows on bridges accounting for the complexity of the hydrodynamic forces to which the bridge is subjected. Moreover, the impact of the reduced service on a bridge on the surrounding network is rarely addressed in literature. Given this limited availability of models, this paper aims to establish rigorous practices of Computational Fluid Dynamics (CFD) for modelling hydrodynamic forces on inundated bridges, and understanding the consequences of such impact on the surrounding network. This aim is achieved by developing an integrated framework to assess the flooding impact on riverine bridges from the structural- to the networklevel (Pregnolato et al., 2020b) and applying it to a real case study in the UK. Objectives of this study are to model hydrodynamic forces as demand on the bridge structure, to advance a reliability analysis of the structure under the modelled loading and to assess the overall impact at systemic level.

This research tackles varying flow conditions (velocity and depth) to understand the structural response across given simulated flooding conditions. This work is novel since it represents a first attempt to couple CFD analysis with both Finite Element (FE) and network analysis for bridges subjected to flooding, in an effort to capture both the cause and effect of flooding. It is expected that this approach will be useful for understanding structural damage and functional loss for a range of bridges, and ultimately to assess risk for any coastal or riverine structure where large-scale water inundation is expected. .

\section{Method}

This paper adopts a risk-based framework to assess the impact of high river flows to bridges and surrounding roads (Figure 1). The framework proposes a comprehensive method that encompasses the traditional four risk modules (hazard, exposure, vulnerability and consequences; Grossi and Kunreuther, 2005) and includes hydrodynamic force modelling, bridge susceptibility to hazard, reliability analysis and network-level impact assessment. This study adopts specific models/software, but the precise sub-models chosen are not critical. In fact, all models/software are interchangeable, and it is reasonable to expect that the approach presented would be appropriate for software packages that ensure similar configuration.

The first step is to determine the intensity measures of flooding in terms of flow depth and velocity (see Section 2.1). For modelling fluvial flooding, most 2D hydrodynamic models can simulate flood depths and flow velocity, for example, LISFLOOD-FP (https://bit.ly/3lstd4j) or TELEMAC (http://www.opentelemac.org/). Bridge information, such as geometry and design, can be retrieved through publicly available databases (if any, e.g. the US National Bridge Inventory) or by dealing with local infrastructure managers and authorities; bridge dimensions, number of piers, material, design principle, foundation type are the main parameters. Unsurprisingly, the availability and accuracy of data influence the modelling outputs.

The second step consists in modelling the interaction between the water and the bridge, as well as the subsequent floodinduced loads. The local flow conditions and corresponding hydrodynamic forces that represent the load on the bridge structure are evaluated Using Computational Fluid Dynamics (CFD) techniques. An example of appropriate CFD software is the $\mathrm{C}++$ toolbox OpenFOAM is the adopted software, being open-source and particularly versatile for the development of customized numerical solvers (https://www.openfoam.org/). 


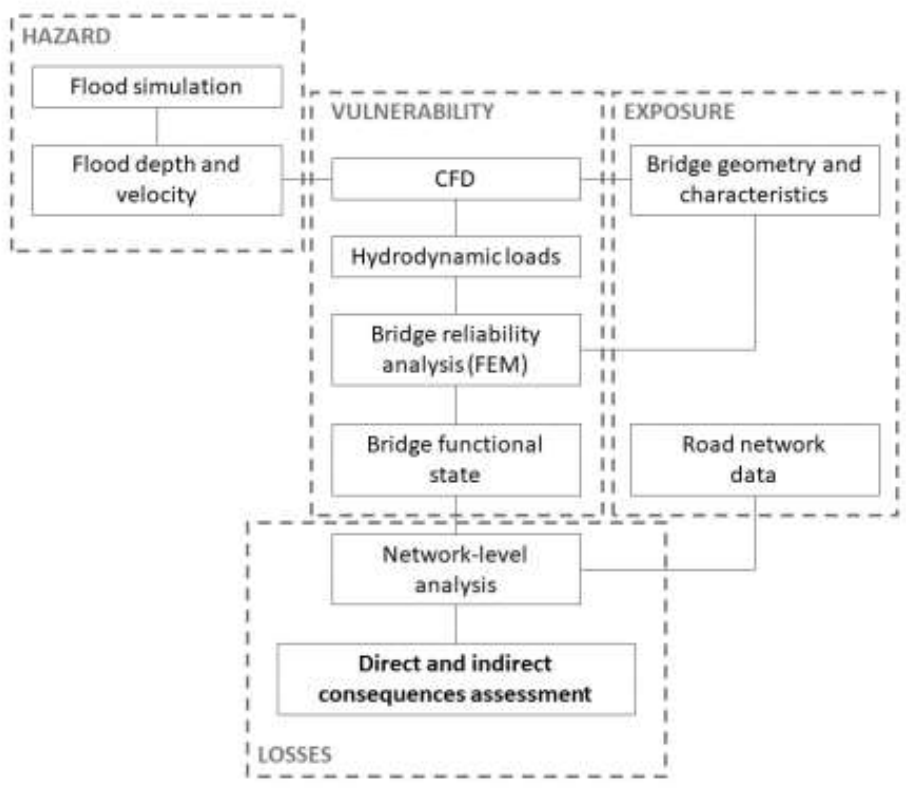

Figure 1: The proposed risk-based methodological flowchart to integrate modelling of hydrodynamic forces, reliability and network-level analysis. Acronyms: CFD - Computational Fluid Dynamics; FEM - Finite Element Model.

The third step is to determine the response of the bridge subjected to flood through a Finite Element (FE) analysis, using line and spring elements to represent the structure. A FE software is functional for this task, such as the OpenSees software framework (McKenna et al., 2010). Mondoro and Frangopol (2018) described salient limit states for bridges subjected to hydraulic loads, and the subset studied in this paper (shown in Figure 2) includes yielding of the girders or piers, unseating or uplift of the girders, failure of the bearings, and excessive global displacement of the superstructure at which transient fluid-structure interaction is important (i.e. the CFD modeling approach is limited).

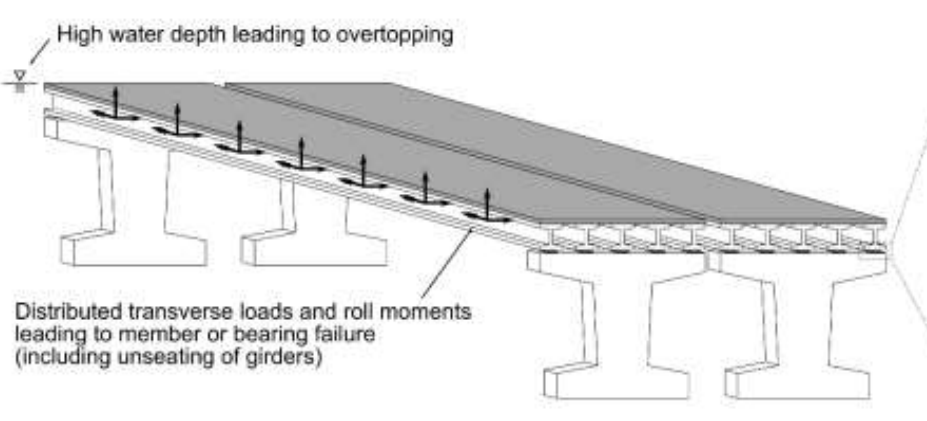

Figure 2: Bridge failure states investigated due to flood loading.

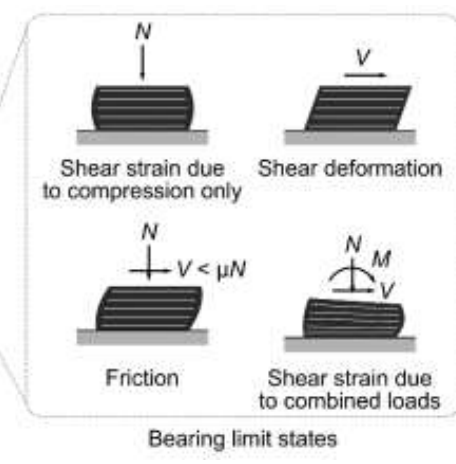

The general limit-states philosophy considers that specifications should satisfy "specified limit states to achieve the objectives of constructability, safety and serviceability" (AASHTO, 2017). In this work, the failure of a bridge is seen as twofold: (i) structural (also strength limit state): when the bridge deck, piers or foundation reach the ultimate limit state or permanent deformations; (ii) functional (also service limit state): when the bridge cannot perform its service as usual. A structural failure directly leads to a functional failure, e.g. the bridge collapses; preventive closure could also take place when bridge conditions are considered unsafe. Nevertheless, a bridge could be unserviceable but still structurally sound, e.g. when floodwater or debris cover the deck. Hydraulic pressures (drag, lift and overturning moment) are assessed for 
potentially dislodging the deck from piers, when submerged or partially sub-merged, and overtopping of the deck is evaluated qualitatively from the CFD model. Though these limit states have significantly different long-term consequences, both result in potential functional failure. The importance of long-term effects should be defined based on local transportation needs.

The last step is to assess consequences, by including the impact of the bridge failure on the wider transport network. Transport models such as ESRITM ArcGIS Network Analyst (https://bit.ly/2GPMknl), SUMO (http://sumo.sourceforge.net/) or MatSIM (https://www.matsim.org/) are suitable for computing routing and delays associated with a disrupted network link (such as a closed bridge). Road network data are publicly available from sources such as Digimap® (https://digimap.edina.ac.uk/), which provides Ordnance Survey road maps. These contain topographic information of roads including name, location, length, capacity and type. After configuring the transportation network model with the collected data, routing and accessibility can be investigated using network-based spatial analysis and transport appraisal techniques (Arrighi et al., 2020; Pregnolato et al., 2016). This impact analysis links the structural damage of a bridge due to flooding with the reduced performance of the local road network the bridge serves for, approximating the wider consequences.

\subsection{Fluvial flooding simulation}

Ideally, boundary conditions should be provided by gauging stations; however, no river gauges are present near the bridge of interest. This study adopted the 2D hydrodynamic model LISFLOOD-FP, which allows to simulate flood depths and flow velocity to set up CFD boundary conditions for a flood scenario and from available gauge data.

LISFLOOD-FP is a two-dimensional, spatially distributed, grid-based hydrodynamic model for simulating channel and floodplain flows (Neal et al., 2009). The model dynamically simulates flood propagation in each grid cell at each time step, on the basis of the local inertial formulation of the shallow water equations and an explicit finite difference method. Numerically, this involves calculating the momentum equation (the flow between cells given the mass in each cell) and the continuity equation (the change in mass in each cell given the flows between cells) (Neal et al., 2018). The equations underpinning the model, including their derivation, can be found in Bates et al. (2010) and de Almeida et al. (2012). As input data, LISFLOOD-FP requires a DEM (Digital Elevation Model) of the area, channel and boundary condition information (e.g. channel friction, width and depth, hydrograph) and evaporation). Flow depth and velocity (for each cell) are the output considered, since they represent the intensity measures of the hazard adopted by this study. The impact of bridges on flow is not explicitly represented in this particular application.

\subsection{Computational fluid dynamics (CFD)}

3D computational fluid dynamics (CFD) software is capable of resolving fine details of flood flow around bridges on a local scale such as splashes, eddies, or flow separation, which cannot be captured by depth-averaged methods (such as LISFLOOD-LP). Also, bridges present a problem for depth-averaged tools since the computational mesh is two-dimensional and cannot be discretized vertically, which does not allow for a gap underneath a bridge superstructure. To accurately model such behaviors is crucial when estimating flow-induced force demands, which requires the use of a fine, three-dimensional mesh. Additionally, using higher fidelity, three-dimensional models allow for localized loads to be measured on individual faces of a structure, which may be used to determine whether or not individual components fail versus entire structures (Winter et al., 2017).

For this study, the three-dimensional CFD code OPenFOAM was selected. Flood flows were modelled using the interFoam solver, which is a two-phase solver that relies upon Volume of Fluid (VoF) method (Tryggvason et al., 2011) to track the interface between water and air phases. The underlying governing equations that are implemented in interFoam are the Reynolds-averaged Navier-Stokes (RANS) equations, which are solved using a predictor-corrector or projection type of method to solve for velocity and pressure fields, and advection equations for the volume fraction introduced by the $\mathrm{VoF}$ 
method. More specifically, pressure-velocity coupling was achieved using the PIMPLE algorithm, which is a combination of the Pressure-Implicit Split-Operator (PISO) and Semi-Implicit Method For Pressure-Linked Equations (SIMPLE). Since the RANS system of equations does not constitute a well-posed system due to the so-called Reynolds stress tensor that arises from the Reynolds-averaging process, a suitable turbulence model that introduces additional equations must be chosen to close the system. For this study, the k- $\omega$ Shear Stress Transport (SST) model was used due to its ability to handle severelyseparated flows near sharp corners better than other similar models such as the Standard, Renormalization Group (RNG), or realizable k- $\varepsilon$ models.

\subsection{Structural analysis}

Finite Element (FE) analysis is commonly employed in the structural engineering community to simulate the response of bridges to natural hazards. Modern bridge superstructures are commonly formed of girders, cap beams, and columns which can be modeled accurately as line elements. Such an approach has been frequently used to model bridges in OpenSees (McKenna et al. 2010) due to its nonlinear modeling capabilities; thus, this software is employed in this study.

OpenSees is seldom used to model structural response to fluids because of the complexity of the fluid loading and the required coupling mechanism between fluid and solid solvers; thus, the present work is among the first of its kind using OpenSees. Other recent research has sought to implement coupling between these multi-physics models. Stephens et al. (2017) demonstrated how OpenSees can be "loosely coupled" (i.e. with no interaction between CFD and FE models) with OpenFOAM to characterize structural response due to sequential earthquake and tsunami loading. A similar loosely coupled scheme is used here, where (i) the bridge deck and girders are modeled as a rigid cross section (i.e. in 2D) and subjected to flood flows at different water depths and velocities in OPenFOAM; (ii) the steady-state reactions on the cross section are recorded; and (iii) the weight of the structure and the steady-state reactions from OpenFOAM are applied as distributed external loads on girder line elements in a 3D OpenSees model representing the bridge superstructure. This OpenSees model is used to evaluate structural limit states such as yielding of the girders, cap beams, or columns; unseating and uplift of the bridge deck; delamination failure of elastomeric bearings, and other limit states associated with large enough deformation to invalidate the assumed configuration of the CFD model.

Since the fluid load is applied to the structure at steady-state conditions, there are no transient effects on the structure and the above limit states can be evaluated using standard practice. In this work, girders and columns are modeled as nonlinear fiberbased line elements capable of simulating concrete cracking and steel yielding. In addition, elastomeric bearing pads are modeled as six-degree-of-freedom elastic springs with shear strain limit states evaluated based on design limits in the American Association of State Highway and Transportation Officials (AASHTO) Load and Resistance Factor Design (LRFD) Bridge Design Specifications (2017) and as recommended by Stanton et al. (2008). To predict girder unseating, the ratio of shear and normal forces on the bearing pads is computed to evaluate frictional demand on the girder-bearing pad interface; similarly, uplift is predicted directly from the normal force developed in the bearing.

According to the level of damage, the structural deficiency is evaluated as slight, moderate, extensive, or complete damage (FEMA, 2003). These four damage states are assigned to discriminate damages which lead to similar loss of functionality and equivalent repair efforts. The qualitative description of these states are adapted for flooding, after the previous work of Padgett et al. (2008) on hurricanes and other HAZUS manual (FEMA, 2003) on earthquakes (Table 1).

Table 1. Bridge damage states (Gehl and D'Ayala, 2018) associated to average repair cost per $\mathbf{m}^{2}$ (Padgett et al., 2008; FEMA, 2003) and average days of closure due to repair (Werner et al., 2008; Gardoni, 2018; Lam and Adey, 2016).

\begin{tabular}{|l|l|l|l|}
\hline Damage state & Description & Average repair cost $\left(\mathfrak{f} / \mathbf{m}^{2}\right)$ & Days of closure \\
\hline Slight & $\begin{array}{l}\text { Minor damages such as cracking (shear } \\
\text { keys, hinges, deck) and spalling (hinges, }\end{array}$ & $£ 1.45 / \mathrm{m}^{2}\left(\$ 0.25 / \mathrm{ft}^{2}\right)$ & $0-5$ \\
\hline
\end{tabular}




\begin{tabular}{|c|c|c|c|}
\hline & $\begin{array}{l}\text { columns) that require no more than cosmetic } \\
\text { repair. Negligible scour. Some water and/or } \\
\text { debris on deck. Full service, likely speed } \\
\text { reduction of travelling vehicles. }\end{array}$ & & \\
\hline Moderate & $\begin{array}{l}\text { Moderate experience of shear cracks and } \\
\text { spalling that still leave columns structurally } \\
\text { sound. Moderate scour and moderate } \\
\text { movement of the abutments. Significant } \\
\text { water and/or debris on deck. The bridge is } \\
\text { partially serviceable (e.g. alternating } \\
\text { circulation, reduced capacity and load), but } \\
\text { safe to use by emergency vehicles. }\end{array}$ & $£ 36.54 / \mathrm{m}^{2}\left(\$ 6.28 / \mathrm{ft}^{2}\right)$ & $5-12$ \\
\hline Extensive & $\begin{array}{l}\text { Degradation of columns without collapse, } \\
\text { shear and cracking leading to structurally } \\
\text { unsafety. Significant residual movement at } \\
\text { connections or major settlement approach. } \\
\text { Delamination failure of individual bearings. } \\
\text { Extensive scour of abutments. The bridge is } \\
\text { closed to traffic. }\end{array}$ & $£ 308.66 / \mathrm{m}^{2}\left(\$ 53.05 / \mathrm{ft}^{2}\right)$ & $13-49$ \\
\hline Complete & $\begin{array}{l}\text { Collapse of columns or connection losing all } \\
\text { bearing support. Imminent deck collapse. } \\
\text { Unseating of girders. Scour leading to } \\
\text { foundation failure. The bridge is } \\
\text { unserviceable. }\end{array}$ & $£ 1102.77 / \mathrm{m}^{2}\left(\$ 189.43 / \mathrm{ft}^{2}\right)$ & $>50$ \\
\hline
\end{tabular}

\subsection{Impact assessment}

The impact of a bridge failure in terms of consequences $(C)$ includes direct consequences $\left(C_{d i r}\right)$ and indirect consequences $\left(C_{\text {ind }}\right)$, which relate the surrounding transport network (Argyroudis et al., 2019). The total costs $C$ is computed as (Eq. 3): $C=C_{\text {dir }}+C_{\text {ind }}=C_{\text {repair }}+C_{\text {cleaning }}+C_{\text {detour }}+C_{\text {delay }}$ where $\mathrm{C}_{\text {repair }}$ is the cost associated with repair or replacement of the bridge, $\mathrm{C}_{\text {clean }}$ is the cost associated with the debris removal (due to flooding), $\mathrm{C}_{\text {detour }}$ is the additional vehicle operating due to the detour and $\mathrm{C}_{\text {delay }}$ is the cost associated with trip delays of normal traffic. Indirect costs may also include a fee for closing the bridge that the bridge owner has to pay to transport operators/agencies (e.g. for railways, highways).

Table 1 lists four identified damage states (from slight to complete), and associated average repair cost and days of closure due to remedial works; the table was developed on existing works and expert opinion. Gehl and D'Ayala (2018) offered a qualitative damage scale of potential damage state and failure modes for the bridge components, which could be associated with functionality losses and remedial actions; Padgett et al. (2008) proposed average repair cost per $\mathrm{m}^{2}\left(\mathrm{ft}^{2}\right)$ to bridges in each damage state (see Sec. 2.3) and these values were functional to compute $\mathrm{C}_{\text {repair. }}$. Average days of closure due to repairs are obtained via discussion with national operators and existing literature (Werner et al., 2008; Gardoni, 2018; Lam and Adey, 2016)

Values for $\mathrm{C}_{\text {clean }}$ can be researched among historic data of bridge owners, e.g. records from bridge inspection reports. $\mathrm{C}_{\text {detour }}$ and $\mathrm{C}_{\text {delay }}$ depend on the network, type of vehicle and traffic flow; this study is limited to consider private cars and HGVs 


$$
\begin{gathered}
C_{\text {detour }}=\sum_{i} \sum_{j} \sum_{z} q_{i, j, z} l_{i, j, z} V O C_{z} \\
C_{\text {delay }}=\sum_{i} \sum_{j} \sum_{z} q_{i, j, z} d_{i, j, z} V T T_{z}
\end{gathered}
$$

(Heavy Goods Vehicles, i.e. over-3.5-tonnes-gross vehicle weight, including both articulated and rigid body types), for the sake of a contained demonstration. According to standard transport appraisal procedures (e.g. DfT, 2009), the parameters are computed with Eq. 4 and Eq. 5 respectively. Considering an origin $i$, a destination $j$ and a vehicle type $z$ :

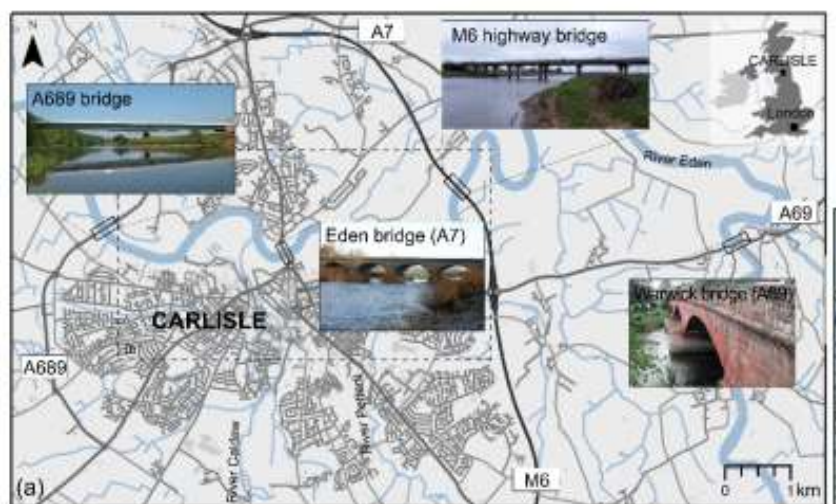

Figure 3. The case study is the city of Carlisle, UK: (a) general overview of Carlisle upon the river Eden, connected North-South by three road bridges (the A689, A7 and M6 bridges) and West-East by the Warwick bridge (A69); (b) flood hazard map for Carlisle, as simulated with LISFLOOD-LP for a 1-in-500-year flood event.

$q$ is the volume of traffic, $\mathrm{l}$ is the incurred additional length, $d$ is the incurred additional time (delay), VOC is the extra Vehicle Operating Cost (including fuel, tear and wear) and VTT is the Value of Travel Time, i.e. the non-monetary costs incurred along the journey as time spent on transport. The additional length and travel time due to the detour are computed using ESRI ${ }^{\mathrm{TM}}$ ArcGIS Network Analyst, setting the origin and the destination of the trip respectively after and before the bridge is flooded (Pregnolato et al., 2016).

\section{Application and results}

The City of Carlisle is a flood-prone city (area: 1,040 km²; 2018 population: 108,387) located in the North West of England (UK) (Figure 3). Three road bridges connect the two parts of the town over the river Eden from North to South (the A689, A7 and M6 bridges) and a fourth one from West to East (Warwick bridge). The 2D hydrodynamic model LISFLOOD-LP was set up to simulate a 1-in-500-year flooding scenario (Fig. 3b) for a domain covering $14.75 \mathrm{~km}^{2}$ of Carlisle, at $5 \mathrm{~m}$ of resolution. This simulation provided flow velocity and inundation height data.

As a proof of concept, the M6 highway bridge over the River Eden was considered. A schematic model of this bridge is shown in Figure 4 with approximate column (reinforced concrete), girder (preflex beam), and elastomeric bearing pad dimensions based on drawings provided by Highways England. Column cross section are $5100 \mathrm{~m} \times 1900 \mathrm{~m}$ (average); the articulation is fixed laminated rubber bearing pads with dowels at the southern end of each span (dimension: $559 \mathrm{~mm} x$ $203 \mathrm{~mm} \times 60 \mathrm{~mm}$ ). The northern ends of span 1 to 7 and the north abutments have free sliding and spherical cylinder bearings (dimension: 500mm x 273/222mm x 114mm). 


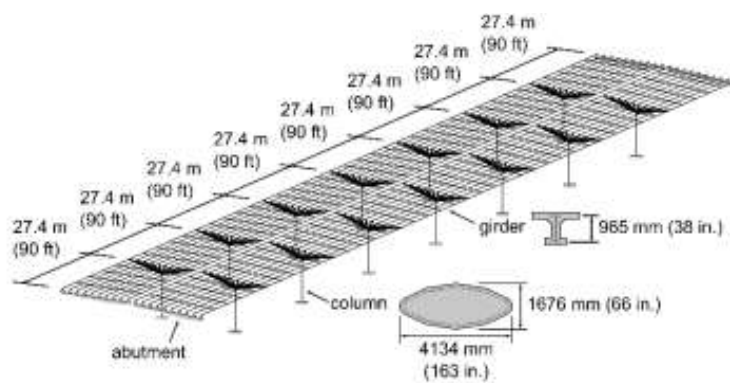

(a) Bridge model and typical member cross sections

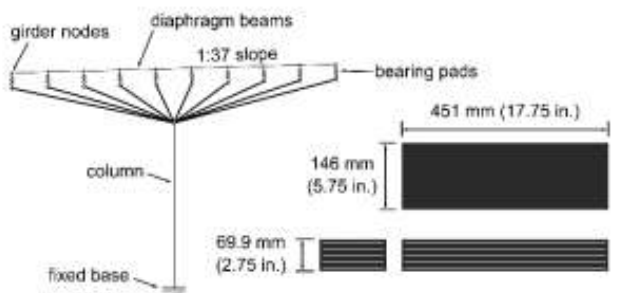

(b) Typical pier model and elastomeric bearing dimențions

Figure 4. Approximate geometry of M6 bridge with column and girder sections shown (sections not to scale).

All input data are summarized in Table 2.

Table 2. Input data of this study for the exemplary CFD analysis of the M6 bridge (Carlisle, UK).

\begin{tabular}{|l|l|l|}
\hline VARIABLE & DATA & SOURCE \\
\hline Span length & $27.4 \mathrm{~m}$ & Drawings provided by Highways England \\
\hline Pier width & $17.1 \mathrm{~m}$ & Drawings provided by Highways England \\
\hline $\begin{array}{l}\text { Superstructure weight } \\
\text { (deck, girders, and diaphragm beams) }\end{array}$ & $514 \mathrm{kN} / \mathrm{m}$ & Derived from drawings \\
\hline Flow Velocity & 1,2, and $3 \mathrm{~m} / \mathrm{s}$ & Modelled (LISFLOOD-LP) \\
\hline Inundation Height & $\begin{array}{l}12.5,13.0,13.5,14.0,14.5, \\
15.0,16.0,17.0,18.0 \mathrm{~m} \text { (from } \\
\text { datum; }+3.2 \mathrm{~m})\end{array}$ & Modelled (LISFLOOD-LP) \\
\hline
\end{tabular}

The simulation was initiated at given inundation heights and flow velocity, as modelled by the LISFLOOD-LP model for a 1in-a-500-year flood event at the site. The OpenFOAM model was set to simulate a range of flow velocity and depth values above and below the calculated 500-year flood results in order to assess how varying the depth and velocity affected the resulting bridge performance. The initial values were extracted in proximity of the bridge, and also compared with historical data overall (peak flow recorded at Sheepmount, UK in December 2015 equal to $1680.0 \mathrm{~m}^{3} / \mathrm{s}$; EA, 2016) and inspection reports. The statistics for the velocity (both in its actual flood flow direction and also normal to the bridge) were computed from the LISFLOOD-LP velocity vectors $\mathrm{Vx} / \mathrm{Vy}$ data and the maximum water depth, for both considering maximum values over the whole flood simulation. The 500-year return period flood showed velocity values up to roughly $3.5 \mathrm{~m} / \mathrm{s}$ and max flood depth up to $17 \mathrm{~m}$ near the M6 Bridge. These statistics motivates using a range of steady-state velocities of 1-3 m/s and inundation heights of 12.5-18 $\mathrm{m}$ above datum (14.8 $\mathrm{m}$ above river bottom) respectively in the OpenFOAM modelling, with the bottom of the bridge's lowest girders at approximately $12.375 \mathrm{~m}$ and the top at $14.425 \mathrm{~m}$ above $+3.2 \mathrm{~m}$ datum. The model measured forces on 20 individual components along the cross-section of the bridge corresponding to girders and each girders' approximate tributary area.

\subsection{Structural analysis and damage assessment}

The OpenSees model was developed using fiber-based line elements for the reinforced-concrete columns and preflex girders (a form of prestressed, concrete-encased steel beams). Nonlinear concrete and steel constitutive models were employed to simulate uniaxial material response. The girders had linear-elastic translational springs at each end to represent elastomeric bearings. The lateral, vertical, and torsional stiffnesses of the bearings were based on linear theory of bearings as described by Stanton et al. (2008) using the dimensions shown in Figure 4 and assuming four, 13-mm-thick layers of elastomer 
reinforced with steel plates. These bearing elements were connected to rigid links which simulated cap beams, providing a load path between the girders and columns. The OPenFOAM reaction forces and roll moments were applied as distributed loads in OpenSees on each bridge girder (i.e. over all eight spans with 20 girders per span). Note that gravity loading was applied prior to the hydraulic loads.

Under the range of loading investigated, yielding or cracking was not detected in the girders or columns, and the simulated hydraulic forces were not large enough to result in uplift of the girders and deck. However, the elastomeric bearing pads sustained large shear demands near the design limits specified by Section 14.7.5 of the AASHTO LRFD Bridge Specification (2017). Specifically, the bearings were evaluated for (1) loss of frictional resistance between the bearing and girder, (2) maximum shear strain due to combined axial load, rotation, and shear displacement; and (3) maximum shear strain due to axial load only.

The solid lines in Figure 5 compare maximum shear deformations and strains in any of the elastomeric bearings for each of the loading scenarios investigated; Figures 5a, 5c, and 5e show these engineering demand parameters versus flow velocity and Figures $5 \mathrm{~b}, 5 \mathrm{~d}$, and $5 \mathrm{f}$ show corresponding values with respect to flow height. The data suggest that peak steady-state demands on any of the elastomeric bearings in the bridge occur around $15 \mathrm{~m}$, at which point the bridge has just reached full inundation. In addition, below a flow height of $15 \mathrm{~m}$, demands consistently increase with velocity. To expand the data set, linear extrapolation to flow velocities of up to $6 \mathrm{~m} / \mathrm{s}$ are shown in Figures 5a, 5c, and 5e as dotted lines with open markers. The Commentary to the AASHTO LRFD Bridge Specification (2017) states a coefficient of friction of 0.2 is appropriate for design, and this limit is used here to evaluate potential unseating of the girders due to lateral hydrodynamic flood load effects. Figures $5 \mathrm{a}$ and $5 \mathrm{~b}$ plot the peak ratios of shear and normal forces across all bearings on the bridge, and it can be observed that the bearings are well under this limit. However, it must be noted that the coefficient of friction may be lower than expected under wet conditions and that the lateral hydrodynamic loading can be significant, increasing vulnerability of unseating due to debris impact. Nevertheless, the results do not indicate unseating due to hydraulic loads, even for a coefficient of friction of 0.1 at an extrapolated velocity of $6 \mathrm{~m} / \mathrm{s}$.

Figures $5 \mathrm{c}$ and $5 \mathrm{~d}$ show peak shear strains on the short edge of the bearing pad (see Figure $4 \mathrm{~b}$ ) due to combined axial load, moment, and shear. On this edge, moment and shear loads are associated with lateral loads (whereas moment and shear loads on the long edge are associated with vertical loads). For design per the AASHTO LRFD Bridge Specification (2017), the combined shear strain due to these actions should not exceed 5.0, and these criteria is satisfied in the analyses. However, the contribution of compression-induced shear strain is more critical: Figures $6 \mathrm{e}$ and $6 \mathrm{f}$ show these data with the annotated shear strain limit of 3.0. It can be seen that at a flow velocity of $3 \mathrm{~m} / \mathrm{s}$ this shear strain limit is approached for flow heights of 12.5, $13.0,13.5$, and $15.0 \mathrm{~m}$. Moreover, between 12.5 and $13.5 \mathrm{~m}$, there is a clear trend of larger strain with increased velocity. When the $13.5-\mathrm{m}$ flow is extrapolated to a velocity of $4 \mathrm{~m} / \mathrm{s}$, this limit is essentially reached and, at $5 \mathrm{~m} / \mathrm{s}$ and higher, multiple flow heights result in exceedance of this limit state. Based on these results, delamination of the bearings due to excessive axial load is the most likely failure mode for the bridge. The plots in Figure 5 show peak demands across all elastomeric bearings in the bridge, and the extent of damage depends on the progression of failure in multiple bearing. 


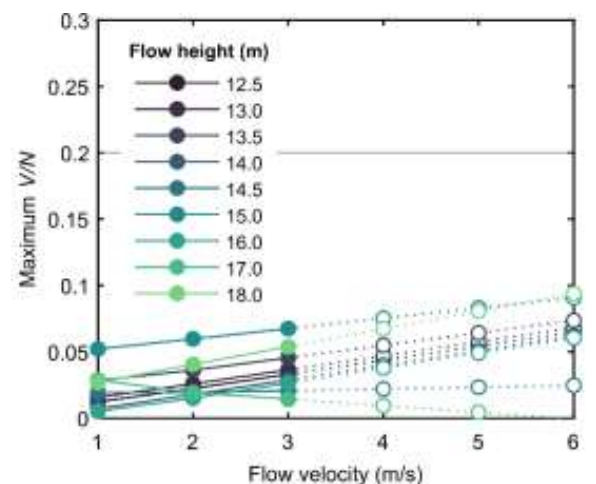

(a)

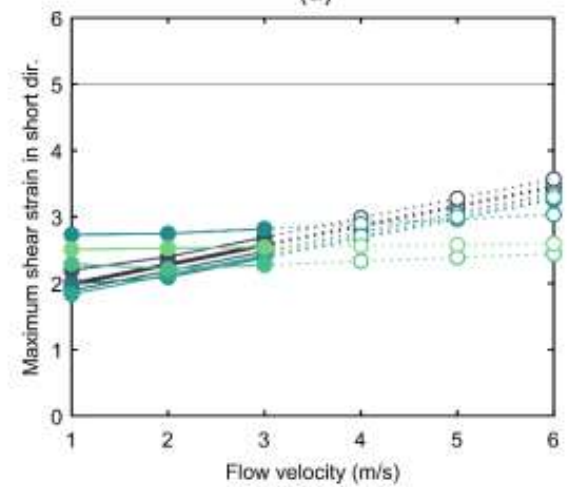

(c)

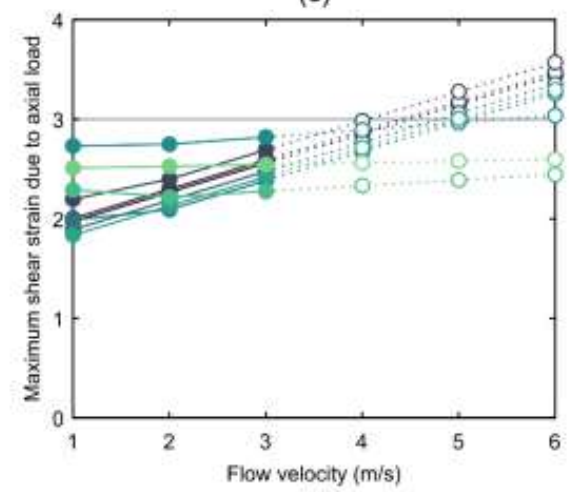

(e)

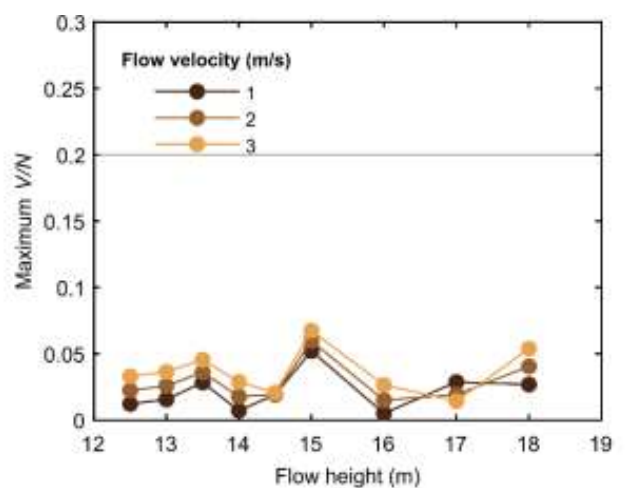

(b)

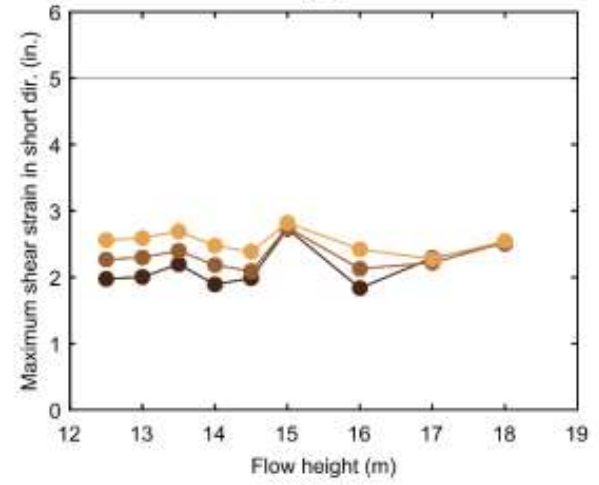

(d)

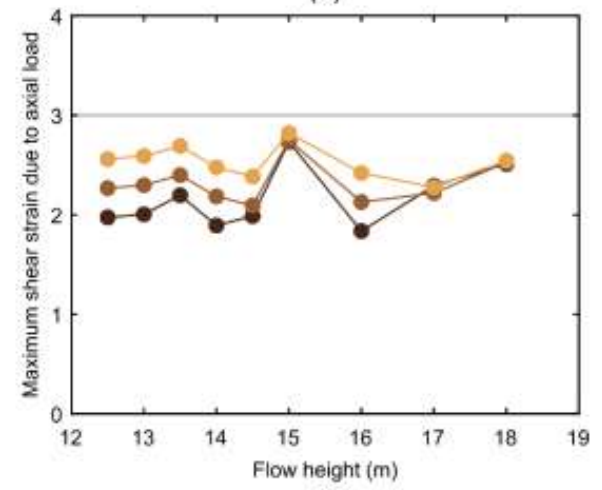

(f)

Figure 5. Simulated demand on elastomeric bearings in M6 bridge evaluated for various limit states; (c) and (d) show peak shear strains on the short edge of the bearing pad, due to combined axial load, moment, and shear.

Scour is also a concern for many riverine bridges, and an example evaluation based on the M6 bridge is shown here using the HEC-18 (FHWA) and CIRIA scour equations. Figure 6 shows estimated scour depths at the bridge piers for worst-case assumptions for soil (i.e. highly mobile soil). For both methods, there is little or no variation with flow depth due to the tall, narrow geometry of the piers. Although the CIRIA scour equation is independent of flow velocity, when the flow velocity exceeds the soil threshold velocity (case shown in Figure 6), its scour depth estimates resulted similar to the FHWA equation for flow velocity between 2 and $3 \mathrm{~m} / \mathrm{s}$. Scour depths in this range (i.e. between 1 and $2 \mathrm{~m}$ ) would likely result in significantly altered foundational restraint and therefore require more sophisticated fluid-soil-structure interaction modelling. Explicit scour modelling was out of the scope of this work, and it is noted that the M6 bridge foundation is cut into sandstone, so significant scour would not be expected in this case study. 


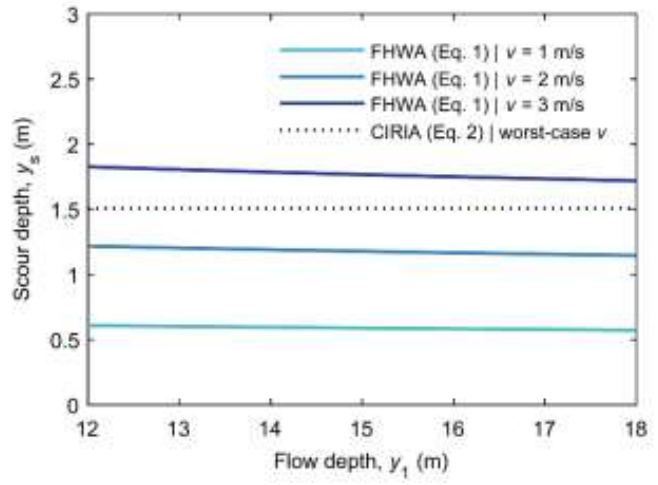

Figure 6. Scour depth for Eden River Bridge using FHWA equation (blue lines) and CIRIA equation (dotted line).

Oveall, the damage state is estimated as moderate (refer to Table 1) because: $(i)$ the bearings approach but do not exceed limit states under the analysed velocities; (ii) scour is not significant; (iii) water level overtop the bridge deck.

\subsection{Network impact and consequence assessment}

A moderate damage state implies the bridge closure for 5-12 days (see Table 1). In the case of the M6 bridge, it closure causes disruptions to all southbound and northbound users that are travelling along the M6 (Figure 7). Compared to the baseline journey, results show that private cars are delayed by 12 minutes and have additional ca. $9 \mathrm{~km}$ due to rerouting. HGVs cannot travel via the historic Eden Bridge (city centre) and are subjected to a longer rerouting, which leads to 19 minutes and ca. $20 \mathrm{~km}$ of delay and additional travelling respectively.

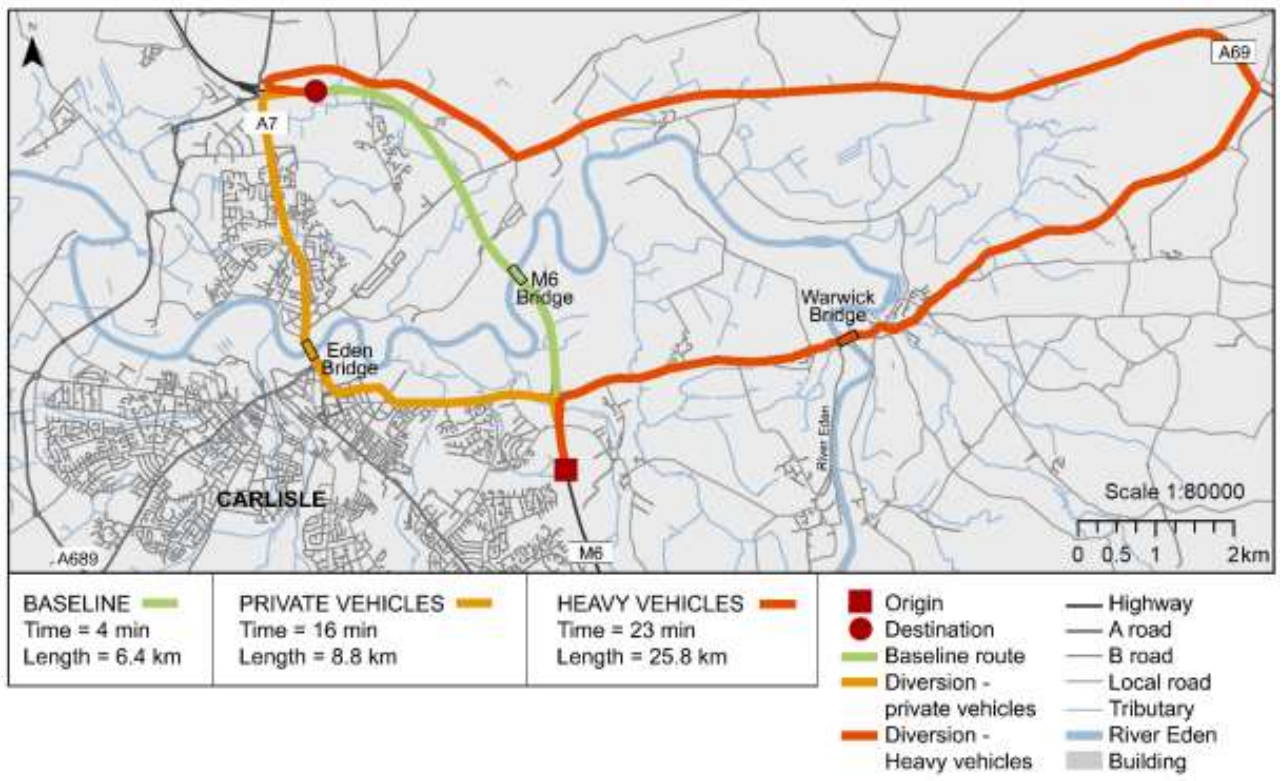

Figure 7. Routes for crossing the river Eden along the highway in baseline and disrupted conditions; private and heavy vehicles are rerouted on different journeys when the M6 bridge is disrupted.

The cost of the impact due to the M6 bridge disruption is computed in terms of direct and indirect consequences using Eq. 3, 4; output and input values are specified in Table 3. 
Table 3. Output and input data for the impact cost calculation considering disruption due to an extreme flood event on the M6 bridge in Carlisle. Acronyms: VTT - Value of Travel Time; HGV - Heavy Good Vehicle; VOC - Vehicle Operating Cost; ADT Average Daily Traffic.

\begin{tabular}{|c|c|c|c|}
\hline & VARIABLE & DATA & SOURCE \\
\hline \multirow{12}{*}{$\begin{array}{l}\text { 占 } \\
\text { 吕 }\end{array}$} & Average repair cost $\left(£ / \mathrm{m}^{2}\right)$ & $£ 36.54 / \mathrm{m}^{2}$ & Table 1 \\
\hline & Time for repairs $\left(\mathrm{T}_{\text {repair }}\right)$ & 7 days & Table 1 \\
\hline & VTT for HGVs & $£ 10.10 /$ hour & DfT (2009) \\
\hline & Delay for HGVs & $19 \min$ & computed \\
\hline & Detour length for HGVs & $19.4 \mathrm{~km}$ & computed \\
\hline & VOC for HGVs & $37.668 \mathrm{p} / \mathrm{km}$ & Blakemore (2018) \\
\hline & ADT for HGVs & $1833 \mathrm{veh} /$ day & UK national statistics \\
\hline & VTT for average private vehicles & $£ 6.81 /$ hour & DfT (2009) \\
\hline & Delay for average private vehicles & $12 \mathrm{~min}$ & computed \\
\hline & Detour length for private vehicles & $2.4 \mathrm{~km}$ & computed \\
\hline & VOC for private vehicles & $25.47 \mathrm{p} / \mathrm{km}$ & Yurday (2020) \\
\hline & ADT for average private vehicles & 28602 veh/day & UK national statistics \\
\hline \multirow{4}{*}{ 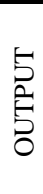 } & $C_{\text {repair }}$ & $£ 7,308.00$ & computed \\
\hline & $C_{\text {clean }}$ & $£ 29,476.00$ & Panici et al. (2020) \\
\hline & $C_{\text {detour }}$ & $£ 30,878.65 /$ day & computed \\
\hline & $C_{\text {delay }}$ & $£ 44,818.47 /$ day & computed \\
\hline & TOTAL & \multicolumn{2}{|l|}{ £566,663.81 } \\
\hline
\end{tabular}

The values of Value of Travel Time (VTT) of HGVs (Heavy Good Vehicles, working condition) and average private cars (unspecified conditions) can be found in the UK Department for Transport (DfT) appraisal methods, illustrated in the Cost Benefit Analysis (COBA) manual (DfT, 2009). Data regarding the additional travel time for rerouting has been computing via transport model (Sec. 2.4) and verified with Google Maps (Figure 7); for the UK, topological road network links are freely available nationwide. Data regarding Average Daily Traffic (ADT) flow are freely available (http://webtris.highwaysengland.co.uk/) and were obtained by considering the annual northbound and southbound flows for the relevant sites (36,670 veh/day: Site 9538/2 on link M6 southbound and Site 9540/2 on link M6 northbound; 2019 data), considering the traffic composition at $78 \%$ for private cars and $5 \%$ for HGVs (DfT, 2019).

The repair cost $\left(C_{\text {repair }}\right)$ was computed using Table 1 and assuming 7 days (average) of bridge closure; the cost of debris removal was obtained by looking at the highest cost for a single event in the UK (Panici et al., 2020), since the simulated flooding is an extreme and rare event. The additional vehicle operating due to the detour per day ( $\left.C_{\text {detour }}\right)$ was calculated using Eq. 4; the cost associated with trip delays $\left(C_{\text {delay }}\right)$ was calculated using Eq. 5.

For the case study undertaken (Carlisle, UK; 1-in-a-500-ys event), the total cost of the flood impact to the bridge is $£ 566,663.81$, considering seven days of bridge closure. The largest proportion (93.5\%) of this cost is due to the indirect cost of rerouting traffic ( $£ 75,697.12$ per day of closure, i.e. $£ 529,879.81)$; the $6.5 \%$ of the total cost is due to direct damages only $(£ 36,784.00)$.

\section{DISCUSSION AND FUTURE RESEARCH}

This study developed an integrated method that couples practices of Computational Fluid Dynamics (CFD) with reliability and network analysis. For the City of Carlisle (UK), a 1-in-500-years flooding event was simulated and the resulting 
hydrodynamic forces on the highway bridge (M6) modelled. While simulated hydrodynamic forces and Finite Element (FE) analysis did not show uplift failure, overtopping of the bridge is shown to occur at inundation heights of $14 \mathrm{~m}$ and above. Given the potential for flood-water disruption of traffic, this should be considered temporary network failure in its own right. For this particular location, the elastomeric bearings supporting the bridge girders approached shear strains near design limits for compression loading. While this limit was not exceeded for flow velocities up to $3 \mathrm{~m} / \mathrm{s}$, extrapolation to faster flow rates suggests potential bearing delamination. This notwithstanding, the bridge would functionally fail at a flow height of between 13.5 and $14.0 \mathrm{~m}$ (i.e. was not fit for purpose) due to inundation of the deck even if the structure sustains no damage. The impact analysis showed that indirect damages covered the $93.5 \%$ of the total cost of damages to the bridge, proving that limiting the assessment to repairs and debris cleaning would greatly underestimate the impact of flooding to bridges. The produced outputs are conceptual results, thus approximate and indicative, for a number of reasons. First, the UK is poor of data regarding bridge repairs, duration time of repair, etc.; research or survey to solicit post-flood data are highly recommended to improve impact estimates. For example, a bridge could be partially closed during repairs (according to its damage state) and allow traffic in one direction. Second, the impact analysis was limited to private cars and HGVs for demonstration purposed; however, advanced transport appraisal could better capture users' choices and the engineering response of lifelines by including a wider range of vehicles categories and traffic scenarios. In terms of impact, the presence of floodwater on the roads is not simulated for limiting the focus of this work on the bridge impact consequences. Flooded roads are likely to cause additional delays to the traffic, so obtained results may underestimated the overall systemic cost. Nevertheless, the proposed approach of impact analysis can give community leaders a robust method for assessing susceptibility to flooding and relative consequences at systemic level.

The importance of this study consists in the proof of concept of a new holistic methodology using a combined CFD-FE approach to improve the fidelity of network failure predictions. The adopted high-fidelity 3D analysis approach allowed to include 3D effects (e.g. variations in the vertical dimension that include the clearances under a bridge) of the flow in the vicinity of the bridge; this is relevant to planners and designers to better predict local fluid pressures that may lead to structural failure. The computed hydrodynamic forces were applied directly into a traditional FE model to predict the global structural response to identify critical structural components and damage states. Notably, the hydrodynamic forces induce large demands on bearings that are not considered in design. Because of the critical nature of bridges to a transportation network, the impact analysis revealed that indirect cost cover almost all the total cost due to flooding; this consideration is fundamental for infrastructure owners and managers when managing assets and budgets.

Next steps of this study will analyze the impact of the closure for a portfolio of bridges, in isolation and any combination of them. Future work should investigate the impacts of other limit states which could result in total or partial bridge closure; a wider range of bridge types should be investigated too. Such analyses would benefit from 3D CFD and FE models to help refining demands on the structure and reducing uncertainty in the predicted bridge reliability. Ultimately, this approach can be applied to any coastal or riverine structure where large-scale water inundation is expected.

\section{CONCLUSION}

This study focused on riverine bridges prone to failures during flood events. This study established rigorous practices of Computational Fluid Dynamics (CFD) for modelling hydrodynamic forces on inundated bridges, and understanding the consequences of such impact on the surrounding network. The hydrodynamic forces were modelled as demand on the bridge structure and inputted into a reliability analysis of the structure; the reliability analysis showed a moderate damage state of the bridge which was used to approximate the overall direct and indirect consequences. For the City of Carlisle (UK) and a 1-in-500-years flooding, results showed that the flood impact to the M6 bridge (highway bridge) caused more than $£ 500 \mathrm{k}$ of damages of which $93.5 \%$ indirect damages (rerouting and delays). The relevance of this work resides in the integrated 
method that couple practices of CFD with reliability and network analysis, which allows to estimate the cost due to flooding impact to a bridge considering the surrounding transport system. Infrastructure owners and managers, as well as modelers and researchers, should build on this work to better predict local fluid pressures that may lead to bridge structural failure and related network economic consequences.

\section{DATA AVAILABILITY STATEMENT}

All relevant and publicly available data will be shared via the DataBris repository of the University of Bristol if the paper will be accepted for publication; data sources are clearly specified throughout the paper.

\section{ACKNOWLEDGEMENTS}

MP was supported by the Engineering and Physical Sciences Research Council (ESPRC) LWEC (Living With Environmental Change) Fellowship (EP/R00742X/1 and 2). The authors also grateful acknowledge: Mark Pooley at Highways England; John L. Kelsall at Phoenix Architecture \& Planning.

\section{References}

AASHTO: Standard specifications for highway bridges, $7^{\text {th }}$ Edition, Washington, DC, 2002

AASHTO: AASHTO LRFD Bridge Design Specifications; $8^{\text {th }}$ Edition, Washington, DC, 2017

Argyroudis, S.A., Mitoulis, S.A., Winter, M.G., Kaynia A.M.: Fragility of transport assets exposed to multiple hazards: State-of-the-art review toward infrastructural resilience, Reliability Engineering \& System Safety 191, 106567, 2019, https://doi.org/10.1016/j.ress.2019.106567

Arneson, L.A., Zevenbergen, L.W., Lagasse P.F., Clopper, P.E.: Evaluating scour at bridges, $5^{\text {th }}$ Edition, Publication no. FHWA-HIF-12-003, Hydraulic Engineering Circular No. 18. U.S. Department of Transportation, Federal Highway Administration, 2012

Arrighi C., Pregnolato M., Dawson R., Castelli F.: Preparedness against mobility disruption by floods, Science of the Total Env., 654: 1010-1022, https://doi.org/10.1016/j.scitotenv.2018.11.191, 2019

Bates P.D., Horritt M.S. and Fewtrell T.J.: A simple inertial formulation of the shallow water equations for efficient twodimensional flood inundation modelling, J. Hydrol. 387(1-2): 33-45. doi: 10.1016/j.jhydrol.2010.03.027, 2010

Blakemore T.: Truck operating costs report for 2018: https://thetruckexpert.co.uk/truck-operating-costs-report-for-2018/ last access: 12 May 2020, 2018

Carey T.J., Mason H.B., Barbosa A.R., Michael H.S.: Multihazard Earthquake and Tsunami Effects on Soil-FoundationBridge Systems, J. Bridge Eng., 24(4), 04019004, doi: https://doi.org/10.1061/(ASCE)BE.1943-5592.0001353, 2019

Department for Transport (DfT): COBA Manual: https://www.gov.uk/government/publications/cobalt-software-and-usermanuals, last access: 12 May 2020, 2009

Department for Transport (DfT): Road Traffic Estimates: Great Britain 2018: https://assets.publishing.service.gov.uk/government/uploads/system/uploads/attachment_data/file/808555/road-trafficestimates-in-great-britain-2018.pdf, last access: 12 May 2020, 2019

de Almeida G.A.M., Bates P.D., Freer J.E., Souvignet M.: Improving the stability of a simple formulation of the shallow water equations for 2-D flood modelling, Water Resour. Res., 48(5), W05528, doi: 10.1029/2011wr011570, 2012

EA: Carlisle Flood Investigation Report 2016. Environment Agency (EA), Cumbria County Council: https://www.cumbria.gov.uk/planning-environment/flooding/flood_investigation_reports_carlisle.asp, last access: 12 November 2020, 2016 
Ertugay K., Argyroudis S. and Düzgün H.Ş.: Accessibility modeling in earthquake case considering road closure probabilities: a case study of health and shelter service accessibility in Thessaloniki, Greece, Int. J. of Disaster Risk Reduction, 17, 49-66, doi: 10.1016/j.ijdrr.2016.03.005, 2016

Gardoni, P.: Routledge Handbook of Sustainable and Resilient Infrastructure. London, Routledge, https://doi.org/10.4324/9781315142074, 2018

Gidaris, I., Padgett, J. E., Barbosa, A. R., Chen, S., Cox, D. T., Webb, B. and Cerato, A.: Multiple-hazard fragility and restoration models of highway bridges for regional risk and resilience assessment in the United States: State-of-the-art review, J. Struct. Eng. 143 (3), 04016188,https://doi.org/10.1061/(ASCE)ST.1943-541X.0001672, 2017

Gehl, P. and D'Ayala, D.: System loss assessment of bridge networks accounting for multi-hazard interactions. Structure and Infrastructure Engineering, 14(10), 1355-1371, 2018

Grossi, P. and Kunreuther, H.: Catastrophe Modeling: A New Approach to Managing Risk, New York, Springer-Verlag, 2005

FEMA: HAZUS-MH MR1: Technical manual, Earthquake Model, Federal Emergency Management Agency, Washington, D.C., 2003

Highways England (HE): Design Manual for Roads and Bridges BD 97/12 The assessment of scour and other hydraulic actions at highway structures: http://www.standardsforhighways.co.uk/ha/standards/dmrb/vol3/section4/bd9712.pdf, last access: 12 May 2020, 2012

Kerenyi, K., Sofu, T. and Guo: J. Hydrodynamic forces on inundated bridge decks, Federal Highway Administration, FHWA-HRT-09-028, 2009

Kilanitis, I. and Sextos, A.: Integrated seismic risk and resilience assessment of roadway networks in earthquake prone areas, Bulletin of Earthquake, 17, 181-210, https://doi.org/10.1007/s10518-018-0457-y, 2019

Kirby, A. M., Roca, M., Kitchen, A., Escarameia, M. and Chesterton, O. J.: Manual on scour at bridges and other hydraulic structures, $2^{\text {nd }}$ edition, CIRIA C742, RP987, London, CIRIA, ISBN: 978-0-86017-747-0, 2015

Lam, J. C. and Adey, B. T.: Integrating functional loss assessment and restoration analysis in the quantification of indirect consequences of natural hazards, ASCE-ASME J. Risk and Uncertainty in Eng. Systems, Part A: Civil Engineering, 2: 04016008, doi: 10.1061/AJRUA6.0000877, 2016

Liu, L., Frangopol, D.M., Mondoro, A. and Yang, D.Y.: Sustainability-Informed Bridge Ranking under Scour Based on Transportation Network Performance and Multi-attribute Utility. J. Bridge Eng., 23(10), 04018082, https://doi.org/10.1061/(ASCE)BE.1943-5592.0001296, 2018

Lomonaco, P., Alam M. S., Arduino, P., Barbosa, A., Cox, D.T., Do, T., Eberhard, M., Motley, M.R., Shekhar, K., Tomiczek, T., Park, H., van de Lindt, J.W. and Winter, A.: Experimental modeling of wave forces and hydrodynamics on elevated coastal structures subject to waves, surge or tsunamis: the effect of breaking, shielding and debris, Coastal Eng. Proceedings 1 (36), 53, https://doi.org/10.9753/icce.v36.waves.53, 2018

McKenna, F., Scott, M.H., and Fenves, G.L.: Nonlinear finite-element analysis software architecture using object composition, J. Comput. Civ. Eng. 24: 95-107, 2010

Mondoro, A. and Frangopol, D.M.: Risk-based cost-benefit analysis for the retrofit of bridges exposed to extreme hydrologic events considering multiple failure modes, Eng. Struct., 159, 310-319, https://doi.org/10.1016/j.engstruct.2017.12.029, 2018

Motley, M.R., Wong, H.K., Qin X., Winter, A.O. and Eberhard, M.O.: Tsunami-induced forces on skewed bridges, J. Waterway, Port, Coastal, Ocean Eng. 142(3), 04015025, https://doi.org/10.1061/(ASCE)WW.1943-5460.0000328, 2016

Neal, J.C., Bates, P.D., Fewtrell, T.J., Hunter, N.M., Wilson, M.D. and Horritt, M.S.: Distributed whole city water level measurements from the Carlisle 2005 urban flood event and comparison with hydraulic model simulations, J. Hydrol., 368(1-4), 42-55, https://doi.org/10.1016/j.jhydrol.2009.01.026, 2009 
Neal, J.C, Dunne, T., Sampson, C., Smith, A. and Bates, P.D.: Optimisation of the two-dimensional hydraulic model LISFLOOD-LP for CPU architecture, Environ. Model. Softw., 107, 148-157, https://doi.org/10.1016/j.envsoft.2018.05.011, 2018

Oudenbroek, K., Naderi, N., Bricker, J.D., Yang, Y., Van der Veen, C., Uijttewaal, W., Moriguchi, S. and Jonkman, S.N.: Hydrodynamic and Debris-Damming Failure of Bridge Decks and Piers in Steady Flow, Geosciences, 8 (11), 409 , https://doi.org/10.3390/geosciences8110409, 2018

Padgett, J.E., DesRoches, R., Nielson, B., Yashinsky, M., Kwon, O.-S., Burdette, M. and Tavera E.: Bridge damage and repair costs from hurricane Katrina, J. Bridge Eng., 13(1), 6-14, https://doi.org/10.1061/(ASCE)1084-0702(2008)13:1(6), 2008

Panici, D., Kripakaran, P., Djordjević, S. and Dentith, K.: A practical method to assess risks from large wood debris accumulations at bridge piers, Science of The Total Environment, 728, 138575, https://doi.org/10.1016/j.scitotenv.2020.138575, 2020

Pregnolato, M., Vardanega, P.J., Limongelli, M. P., Giordano, P. F. and Prendergast, L. J. Risk-based scour management: a survey, In Bridge Maintenance, Safety, Management, Life-Cycle Sustainability and Innovations, Proceedings of the $10^{\text {th }}$ International Conference on Bridge Maintenance, Safety and Management (IABMAS 2020), Yokota, H. and Frangopol, D.M. (eds), CRC Press, Boca Raton, FL, USA, 2020a

Pregnolato, M., Winter, A.O., Mascarenas, D., Sen, A.D., Bates, P. and Motley, M.R.: An integrated impact analysis for riverine bridges subjected to high river flows, In Bridge Maintenance, Safety, Management, Life-Cycle Sustainability and Innovations, Proceedings of the $10^{\text {th }}$ International Conference on Bridge Maintenance, Safety and Management (IABMAS 2020), Yokota, H. and Frangopol, D.M. (eds), CRC Press, Boca Raton, FL, USA, 2020b

Pregnolato, M.: Bridge safety is not for granted - A novel approach for bridge management, Eng. Structures, 196, 109193, https://doi.org/10.1016/j.engstruct.2019.05.035, 2019

Pregnolato M., Ford A., Robson C., Glenis V., Barr, S. and Dawson R.J.: Assessing Urban Strategies for Reducing the Impacts of extreme Weather on Infrastructure Networks, Royal Soc. Open Sci., 3(5), 1-15, doi: 10.1098/rsos.160023, 2016

Qin, X., Motley, M.R. and Marafi, N.: Three-dimensional modeling of tsunami forces on coastal communities, Coast. Eng., 140, 43-59, https://doi.org/10.1016/j.coastaleng.2018.06.008, 2018

Solomon, S., Manning, M., Marquis, M. and Qin, D.: Climate change 2007 - the physical science basis: Working group I contribution to the $4^{\text {th }}$ assessment report of the IPCC, Cambridge University Press, Cambridge, 2007

Stanton, J. F., Roeder, C. W., Mackenzie-Helnwein, P., White, C., Kuester, C., and Craig, B.: Rotation Limits for Elastomeric Bearings, NCHRP Report 596, The National Academies Press, Washington D.C., doi: 10.17226/23131, 2008 Stephens, M.T., Winter, A., Motley, M.R., and Lehman, D.E.: Comparing seismic and tsunami load de-mands on reinforced concrete and concrete filled steel tube bridges, Proceedings of the $39^{\text {th }}$ IABSE Symposium, 2017

Tryggvason, G., Scardovelli, R. and Zaleski, S.: Direct numerical simulations of gas-liquid multiphase flows, Cambridge University Press, Cambridge, 2011

Yang, D. Y. and Frangopol, D.: Life-cycle management of deteriorating bridge networks with network-level risk bounds and system reliability analysis, Struct. Safety, 83, 101911, https://doi.org/10.1016/j.strusafe.2019.101911, 2020

Yilmaz, T., Banerjee, S. and Johnson, P. A.: Performance of two real-life California bridges under regional natural hazards. J. Bridge. Eng. 21(3), 1-15, https://doi.org/10.1061/(ASCE)BE.1943-5592.0000827, 2016

Yurday, E.: Average Cost to Run a Car UK 2020: https://www.nimblefins.co.uk/average-cost-run-car-uk, last access: 12 May 2020, 2020

Wang, C., Yu, X. and Liang, F.: A review of bridge scour: mechanism, estimation, monitoring and countermeasures, Nat. Hazards, 87, 1881-1906, https://doi.org/10.1007/s11069-017-2842-2, 2017 
https://doi.org/10.5194/nhess-2020-375

Preprint. Discussion started: 23 December 2020

(C) Author(s) 2020. CC BY 4.0 License.

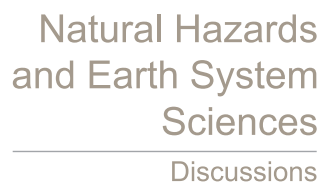

Wardhana, K. and Hadipriono, F. C.: Analysis of Recent Bridge Failures in the United States, J. Perf. of Constructed Facilities 17(3), 144-150, https://doi.org/10.1061/(ASCE)0887-3828(2003)17:3(144), 2003.

531 Werner, S. D., Cho, S. and Eguchi, R. T.: The ShakeOut Scenario Supplemental Study: Analysis of Risks to Southern California Highway System, SPA Risk LLC, Denver, CO, 2008

Winter A.O., Motley M.R. and Eberhard M.O.: Tsunami-like wave loading of individual bridge components, J. Bridge Eng. 23 (2), 04017137, https://doi.org/10.1061/(ASCE)BE.1943-5592.0001177, 2017

535

Zhou, Y., Banerjee, S. and Shinozuka, M.: Socio-economic effect of seismic retrofit of bridges for highway transportation networks: a pilot study, Struct. Infrastruct. Eng. 6, 145-157, https://doi.org/10.1080/15732470802663862, 2010 